\title{
Ultrasonography for Localization of Subcentimetre Lung Nodules
}

\author{
Incekara $F^{*}$, Findik G, Apaydın SMK, Demiroz SM and Erturk H
}

Department of Thoracic Surgery, Atatürk Chest Diseases and Thoracic Surgery Research and Training Hospital, Ankara, Turkey

*Corresponding author: Incekara F, Department of Thoracic Surgery, Atatürk Chest Diseases and Thoracic Surgery Research and Training Hospital, Ankara, Turkey, Tel: +905057682387; E-mail: drfundaincekara@gmail.com

Received date: May 9, 2017; Accepted date: July 13, 2017; Published date: July 20, 2017

Copyright: $\odot 2017$ Incekara F. This is an open-access article distributed under the terms of the Creative Commons Attribution License, which permits unrestricted use, distribution, and reproduction in any medium, provided the original author and source are credited.

\begin{abstract}
Localization of deeply, small, non-visible and non-palpable subcentimetre nodules can be difficult during videoassisted thoracoscopic surgery (VATS) and even during minithoracotomy. Linear ultrasound probe helps surgeon find these undetermined nodules by VATS or thoracotomy technique without any need of digital palpation and has been demonstrated a safe and feasible technique alternative to computed tomography guided procedure (coils, hook wires, methylene blue, lipidol and barium staining). Herein, we describe a case who we preoperatively labeled peripheral lung lesion in the right lower lobe with methylene blue digitalization were not possible by palpation and peripheral two lesions were successfully demonstrated with the use of linear ultrasound probe during thoracic surgery.
\end{abstract}

Keywords: Linear ultrasound probe; Subcentimetre nodules; Nonpalpable nodules; Minimally invasive surgery; Port access; Minithoracotomy

\section{Introduction}

The use of ultrasonography for the localization of lung nodules has been reported since in the 1990s [1-8]. Although described in 1990s this technology has not been fully adapted to thoracic surgery. This technique can be applied to any pleural surface in the thoracic cavity. Localization of deeply, small, non-visible and non-palpable subcentimetre nodules cannot be easily identified. We describe one case of peripheral two lesions' digitalization were not possible by palpation that were successfully demonstrated with the use of linear ultrasound probe during thoracic surgery.

\section{Case Report}

A 67 year old man without known common disease pulmonary nodules were detected during routine examinations and evaluated for further examination. He learned to smoke 30 packs per year on his resume. There was no history of chest pain, breathlessness, fever, loss of weight and hemoptysis. There was no significant difference in physical examination. No pathology was observed in the sputum smear examination. No endobronchial lesion on flexible bronchoscope.

On chest radiograph, a solitary pulmonary nodule $15 \times 8 \mathrm{~mm}$ was detected in the right upper zone and the other solitary pulmonary nodule $8 \times 6 \mathrm{~mm}$ was detected in the right lower zone that were subsequently confirmed on contrast enhanced computed tomography (CT) of the thorax; $15 \times 8 \mathrm{~mm}$ irregularity in the right upper lobe apical segments, right upper lobe posterior segment causing pleural scoring; $8 \times 7 \mathrm{~mm}$ parenchymal nodules were observed. PET-CT showed low involvement (SUV:1.20) and malignancy could not be ruled out. The operation was decided with video-assisted thoracoscopic surgery (VATS) (Figures 1).

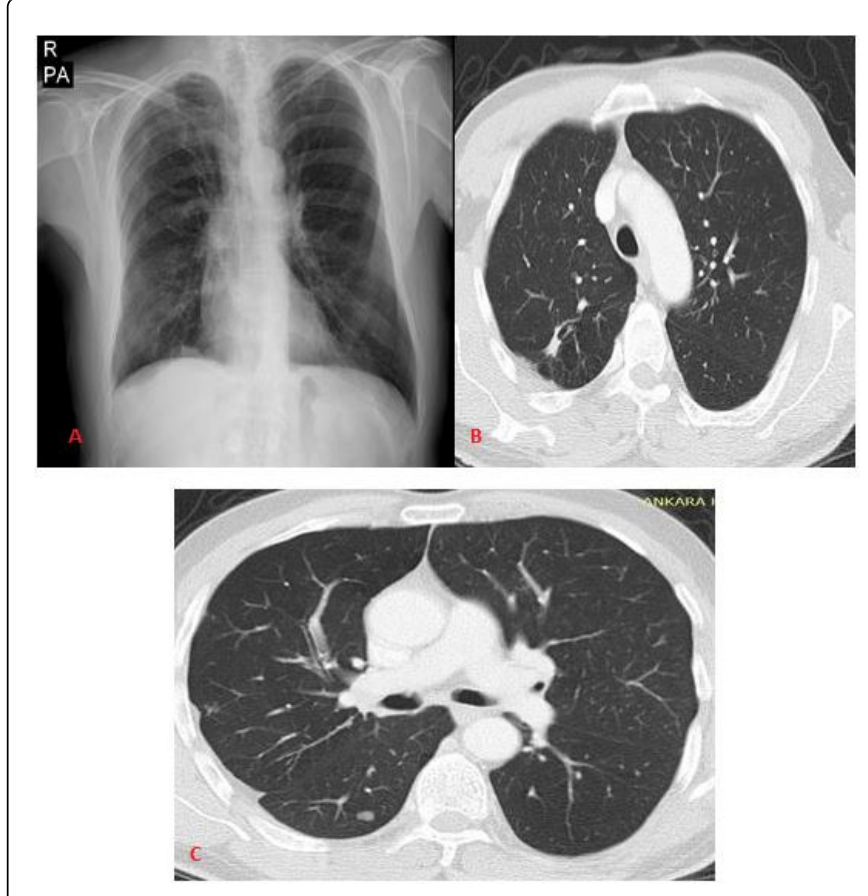

Figure 1: A: Chest radiograph; B: On contrast enhanced computed tomography $(\mathrm{CT})$ of the thorax $15 \times 8 \mathrm{~mm}$ irregularity; $\mathrm{C}$ : $\mathrm{On}$ contrast enhanced computed tomography $(\mathrm{CT})$ of the thorax $8 \times 7$ mm parenchymal nodule.

The radiology clinic was consulted for marking with preoperative methylene blue. Nodule in the lower lobe marking was performed with methylene blue on CT-guided before the operation. The nodule in the right lower lobe marked with the right VATS could not be palpated.

We could then visualize the nodules in the upper and lower lobes with an intrathoracic linear probe ultrasonography with VATS (Figure 2). The utility incision that we opened for use in the VATS method was 
expanded by $2 \mathrm{~cm}$ for minithoracotomy. And then the nodules in the parenchyma as well as the vascularization of the tissues around these nodules were imaged using an intraoperative linear ultrasonic probe.

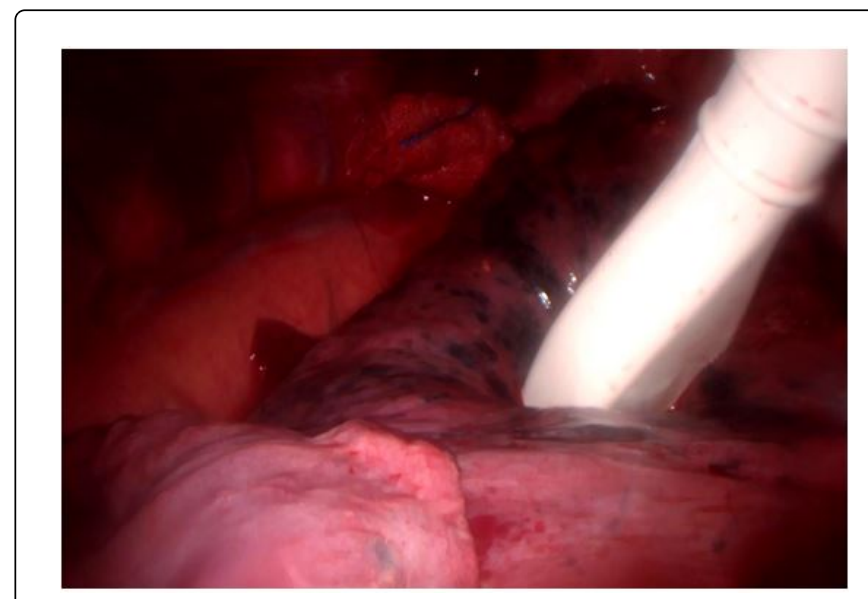

Figure 2: Intrathoracic linear probe ultrasonography with VATS.

These areas in the upper and lower lobes wedge resection was performed with parenchyma staples. The nodule was in upper lobe reported as fibrotic tissue the other nodule was in lower lobe reported as lymph node (Figures 3 ).

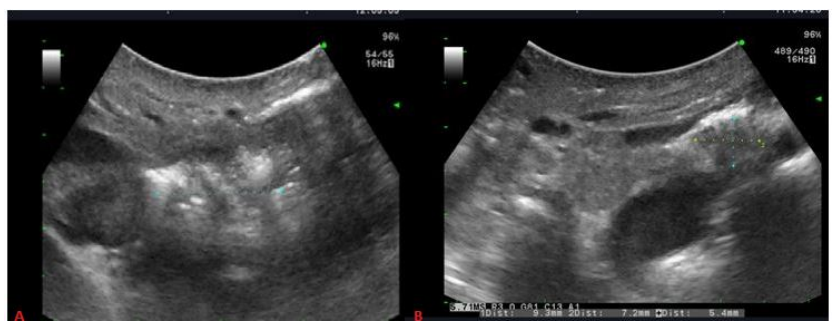

Figure 3: A: Intraoperative ultrasonic image of $15 \times 8 \mathrm{~mm}$ irregularity; B: Intraoperative ultrasonic image of $8 \times 7 \mathrm{~mm}$ parenchymal nodule.

\section{Discussion}

The need to investigate peripheral lung nodules is a commonly encountered clinical situation in thoracic surgeons. VATS is a useful minimally invasive procedure for the diagnosis and treatment of these nodules. However, as such lesions may not be visible or palpable during VATS; conversion from VATS to thoracotomy is occasionally conducted following failure to localize these lesions $[9,10]$. Therefore, it is crucial to accurately localize lesions prior to VATS and even during thoracotomy particularly in the case of small or non-visible and non-palpable nodules. The common localization method is the computed tomography guided procedure (coils, hook wires, methylene blue). However, this technique is associated with the development of pneumothorax and wires maybe dislodged with movement [11]. The most commonly used dye, methylene blue may diffuse quickly to the uninvolved pleural surface and make localization difficult $[12,13]$. In our case, methylene blue marking was applied in the guideline of CT for the nodules. However, it was not possible to reach these nodules.
Ultrasonography is a procedure with a specific value in the investigation of peripheral non-palpable lung nodules during thoracic surgery. Extrathoracic ultrasonography can be used successfully in the diagnosis of pleural conditions. It was used under local anesthesia and also in children with VATS $[1,6-14]$. Ultrasonography was applied to 85 patients with different indications. Developed an intrathoracic ultrasonic probe and used it in 61 patients during thoracoscopy and 24 patients during open thoracic surgery. Their study showed that thoracoscopic had high sensitivity for localization of intrapulmonary tumors [1]. Wada and colleagues convex probe ultrasound was used in their study was to assess thoracoscopic localization and biopsy of subcentimetre pulmonary nodules in porcine and rabbit lung models [2]. With the ultrasound compared in terms of the size and depth of the tumors. In Kondo et al. study they included 44 patients where 53 lesions were localized and resected [8]. The whole area of intraoperative ultrasonography accurately identifies the anatomical structures of parenchyma and ground glass opacities. USG application in operation is preferable when these methods are inadequate and these nodules can be displayed without problems.

In our interventional radiology service, marking with methylene blue was performed in the thorax CT correspondence and then the patient was taken to the operation room. During the operation the nodules could not be detected even with palpation and we decided to apply linear USG, which is sterile as a last resort. During the operation with the help of the radiologist two nodules were shown with the aid of the usg. In addition the region of the parenchymal wedge with minithoracotomy, lymph nodes and fibrotic tissue were present in the pathology report. So we showed the localization of the nodules.

In conclusion, ultrasonography can also be used as a simple, economic tool for guiding puncture biopsy during thoracic surgery. In the present case, ultrasound exam was used to accurately locate the pulmonary tumor and to guide the surgical operations during thoracic surgery. Thus, we conclude that ultrasound exam would be a helpful diagnostic tool for differentiating between thoracic visceral lesions and parietal lesions, locating peripheral pulmonary tumors and guiding surgical thoracoscopy or minithoracotomy and pathological examination in this context.

\section{References}

1. Friedel G, Hurtgen M, Toomes H (1998) Intraoperative thoracic sonography. Thora cardio surg 46: 147-151.

2. Wada H, Anayama T, Hirohashi K, Nakajima T, Kato T, et al. (2016) Thoracoscopic ultrasonography for localization of subcentimetre lung nodules. Eur J Cardiothorac Surg 49: 690-697.

3. Piolanti M, Coppola F, Papa S, Pilotti V, Mattioli S, et al. (2003) Ultrasonographic localization of occult pulmonary nodules during videoassisted thoracic surgery. Eur Radiol 13: 2358-2364.

4. Matsumoto S, Hirata T, Ogawa E, Fukuse T, Ueda H (2004) Ultrasonographic evaluation of small nodules in the peripheral lung during video-assisted thoracic surgery (VATS). Eur J Cardiothorac Surg 26: 469-473.

5. Khereba M, Ferraro P, Duranceau A, Martin J, Goudie E, et al. (2012) Thoracoscopic localization of intraparenchymal pulmonary nodules using direct intracavitary thoracoscopic ultrasonography prevents conversion of VATS procedures to thoracotomy in selected patients. J Thorac Cardiovasc Surg 144: 1160-1165.

6. Gow KW, Saad DF, Koontz C, Wulkan ML (2008) Minimally invasive thoracoscopic ultrasound for localization of pulmonary nodules in children. J Pediatr Surg 43: 2315-2322.

7. Rocco G, Cicalese M, La Manna C, La Rocca A, Martucci N, et al. (2011) Ultrasonographic identification of peripheral pulmonary nodules 
Citation: Incekara F, Findik G, Apaydin SMK, Demiroz SM, Erturk H (2017) Ultrasonography for Localization of Subcentimetre Lung Nodules. J Clin Respir Dis Care 3: 131. doi:10.4172/2472-1247.1000131

Page 3 of 3

through uniportal video-assisted thoracic surgery. Ann Thorac Surg 92: 1099-1101.

8. Kondo R, Yoshida K, Hamanaka K, Hashizume M, Ushiyama T, et al. (2009) Intraoperative ultrasonographic localization of pulmonary ground-glass opacities. J Thorac Cardiovasc Surg 138: 837-842.

9. Chen S, Zhou J, Zhang J, Hu H, Luo X, et al. (2011) Video-assisted thoracoscopic solitary pulmonary nodule resection after CT-guided hookwire localization: 43 cases report and literature review. Surg Endosc 25: 1723-1729.

10. Suzuki K, Nagai K, Yoshida J, Ohmatsu H, Takahashi K, et al. (1999) Video-assisted thoracoscopic surgery for small indeterminate pulmonary nodules: Indications for preoperative marking. Chest 115: 563-568.

11. Horan TA, Pinheiro PM, Araujo LM, Santiago FF, Rodrigues MR, et al. (2002) Massive gas embolism during pulmonary nodule hook wire localization. Ann Thorac Surg 73: 1647-1649.
12. Iwasaki Y, Nagata K, Yuba T, Hosogi S, Kohno K, et al. (2005) Fluoroscopy-guided barium marking for localizing small pulmonary lesions before video-assisted thoracic surgery. Respir Med 99: 285-289.

13. Findik G, Demiroz SM, Apaydın SM, Erturk H, Biri S, et al. (2017) Computed tomography-guided methylene blue labeling prior to thoracoscopic resection of small deeply placed pulmonary nodules. Do we really need palpation. Thorac Cardiovasc Surg.

14. Medford AR (2010) The utility of thoracic ultrasound before local anesthetic video-assisted thoracoscopy in patients with suspected pleural malignancy. J Clin Ultrasound 38: 222-225. 